Ann. rheum. Dis. (1957), 16, 230.

\title{
MYALGIC SYNDROME WITH CONSTITUTIONAL EFFECTS POLYMYALGIA RHEUMATICA
}

\author{
BY
}

\author{
H. STUART BARBER \\ Manchester
}

(RECEIVED FOR PUBLICATION SEPTEMBER 21, 1956)

At two rheumatism clinics within the past 6 years several patients have been seen with symptoms suggestive of rheumatoid disease, but who on examination were found to lack the usually associated clinical signs. The impression that the condition might be a clinical entity has grown stronger with continued observation over a period of years, and increasing awareness of the clinical features disclosed that several other such cases were attending the clinics with the presumptive diagnosis of rheumatoid disease. These cases have been under observation for from 1 to 10 years, and none has developed the clinical features of rheumatoid disease in this time although many have continued to have painful muscle symptoms of variable intensity. Of the twelve patients, two were men and ten women, their ages at onset ranging from 46 to 68 years. One man has been under continuous personal observation for 7 years.

Symptoms. - The onset is characterized by widespread muscular pain, often as sudden as the familiar stiff neck so well named "Hexenschuss" by the Germans. Sometimes it is a more gradually increasing ache affecting the neck and shoulder muscles or the lower back and thigh muscles. As in other forms of rheumatism, there are seemingly no significant aetiological factors and the onset could not be related to a preceding infection or emotional upset. The site of onset in the present series of cases was either in the neck and shoulders or in the gluteal region and thighs. In one case the pain first appeared in the calf muscles and several patients referred to pain in the hips which on closer inquiry was clearly located in the gluteal muscles.

In all cases, muscle-groups of the trunk and limbs successively became affected and by the time the patients were seen at the clinic the discomfort was so widespread as to evoke the consideration of a psychogenic basis. Nor was this impression lessened by the apparent exaggeration of the symptoms.
It is the similarity of the description which becomes so striking. Two patients had "pain from the neck to the knees", and complaints of pain "from the buttocks to the ankles", "in shoulders and groins", "in knees, thighs, hips, and neck" were the rule. One man described himself as having a "burning, searing pain in the shins". None of the patients had had swollen joints despite the presence of these painful symptoms for periods ranging from 3 months to 5 years.

Not unnaturally the complaint had been treated as "fibrositis" or "muscular rheumatism" and salicylates afforded the usual temporary relief. However, the persistence of the pains, their widespread character, and the presence of constitutional symptoms led the patients to be referred to the clinics. Most patients had experienced loss of weight since the onset, in one case of $28 \mathrm{lb}$. Sleep was much disturbed by pain and all complained of lassitude and depression. A few patients mentioned some degree of morning stiffness apparently similar to that found in rheumatoid disease.

The clinical findings on examination were characterized by the absence of objective joint changes. In cases with pain the neck and shoulders there was slight limitation of movement which could be largely attributed to painful muscles. No restriction of movement was found in the lower limbs even when the pain was located there. No abnormality was found in the lungs, cardiovascular system, abdomen, or the central nervous system.

Laboratory Findings.-These are summarized in the Table (opposite). The erythrocyte sedimentation rate was always raised and often extremely high. A hypochromic anaemia was not infrequent but the blood count in other respects was normal. All the present cases showed a hyperglobulinaemia.

In nine a search was made for "L.E." cells but these were not found.

The differential sheep cell agglutination test, which 
TABLE

INITIAL LABORATORY FINDINGS

\begin{tabular}{|c|c|c|c|c|c|c|c|c|c|c|c|c|}
\hline Case No. & 1 & 2 & 3 & 4 & 5 & 6 & 7 & 8 & 9 & 10 & 11 & 12 \\
\hline $\begin{array}{l}\text { Erythrocyte Sedimenta- } \\
\text { tion Rate (mm./hr } \\
\text { Westergren) }\end{array}$ & 55 & 55 & 100 & 45 & 80 & 110 & 85 & 75 & 90 & 80 & 65 & 110 \\
\hline Hb (g. \%) & $9 \cdot 1$ & $9 \cdot 6$ & $9 \cdot 6$ & $11 \cdot 7$ & $12 \cdot 5$ & $9 \cdot 8$ & $8 \cdot 6$ & $11 \cdot 6$ & $12 \cdot 2$ & 14 & $13 \cdot 3$ & $12 \cdot 1$ \\
\hline $\begin{array}{l}\text { Red Blood Cells } \\
\text { (mill./c.mm.) }\end{array}$ & $4 \cdot 1$ & $4 \cdot 1$ & $3 \cdot 7$ & $4 \cdot 4$ & $4 \cdot 5$ & $4 \cdot 0$ & $2 \cdot 9$ & $4 \cdot 3$ & $4 \cdot 5$ & $4 \cdot 8$ & $5 \cdot 1$ & $4 \cdot 6$ \\
\hline White Blood Cells & 8,700 & 5,400 & 5,100 & 4,200 & 7,200 & 7,600 & 7,400 & 6,400 & 4,200 & 10,700 & 7,200 & 8,400 \\
\hline $\begin{array}{l}\text { Serum Albumin } \\
(\mathrm{g} . / \mathrm{ml} . \%)\end{array}$ & $3 \cdot 34$ & $3 \cdot 3$ & $2 \cdot 75$ & $3 \cdot 4$ & $4 \cdot 0$ & $3 \cdot 6$ & $3 \cdot 6$ & $4 \cdot 8$ & $4 \cdot 2$ & $3 \cdot 5$ & $3 \cdot 9$ & $3 \cdot 5$ \\
\hline $\begin{array}{l}\text { Serum Globulin } \\
(\mathrm{g} . / \mathrm{ml} . \%)\end{array}$ & $3 \cdot 1$ & $3 \cdot 9$ & $4 \cdot 0$ & $3 \cdot 0$ & $3 \cdot 8$ & $3 \cdot 7$ & $3 \cdot 3$ & $3 \cdot 0$ & $3 \cdot 2$ & $3 \cdot 9$ & $3 \cdot 0$ & $3 \cdot 4$ \\
\hline Thymol Turbidity & 一 & $1 \cdot 5$ & 一 & - & $3 \cdot 5$ & 2 & 一 & 1 & 一 & 1 & 3 & 1 \\
\hline Blood Urea & - & 20 & - & - & 27 & - & 24 & 26 & 30 & - & 一 & 31 \\
\hline $\begin{array}{l}\text { Standard Urea } \\
\text { Clearance }(\%)\end{array}$ & 68 & 67 & 43 & - & 84 & - & 97 & 86 & 50 & - & - & 44 \\
\hline “L.E." Cells & - & Neg. & - & - & Neg. & Neg. & Neg. & Neg. & Neg. & Neg. & Neg. & Neg. \\
\hline Wassermann Reaction & 一 & Neg. & 一 & 一 & Neg. & Neg. & Neg. & Neg. & Neg. & 一 & Neg. & Neg. \\
\hline D.A.T. & - & Neg. & Neg. & - & Neg. & Neg. & Neg. & Neg. & Neg. & Neg. & Neg. & Neg. \\
\hline
\end{tabular}

(according to certain clinical features) is positive in 57-95 per cent. of in-patients with rheumatoid disease, was negative in all cases tested (Ball, 1956).

Some apparent impairment of renal function was found in two cases in which the standard urea clearance was respectively 43 and 44 per cent. of average normal function, although the blood urea was within normal limits.

Alterations in the plasma proteins reflect changes in liver function, and the thymol turbidity test will detect such changes which not infrequently occur in rheumatoid disease, but in seven of the present cases in which the test was carried out normal results were obtained.

The Wassermann reaction, which occasionally shows a false-positive result in systemic lupus erythematosus, was negative in the six patients whose blood was tested.

A latent thyrotoxicosis was considered in two patients, but their serum cholesterol and basal metabolic rates were found to be normal.

In two cases in which it was done the Widal reaction was negative for the Salmonella typhi, $S$. paratyphi, and Brucella abortus groups.

The radiographic appearances of the hands showed the presence of some degree of osteoporosis, but this was neither juxta-articular nor accompanied by the characteristic erosions seen in rheumatoid disease. In the skiagrams of the spine only changes of a degenerative nature consistent with the age of the patient were present.
Treatment.-All patients were given a prolonged period of rest in bed and daily active non-weightbearing exercises under the supervision of a physiotherapist. Pain could be controlled to a large extent by salicylates, codeine, or phenylbutazone. Hypochromic anaemia was corrected by parenteral iron as necessary. Pyrexia occurred in two patients, one of whom had a persistently raised temperature accompanied by night sweats. All investigations to ascertain the cause of this pyrexia proved fruitless and it gradually settled to normal. During this period she developed a widespread vitiligo which is still present 12 months after her discharge from hospital.

The acute phase of pain gradually passed off under this regime, but in many cases the erythrocyte sedimentation rate remained high. The greater availability of the corticosteroids made it possible to try their effect, and there was no doubt of the immediate response to these preparations. Three patients obtained almost complete relief with phenylbutazone and continue to take this in preference to any other drug.

Prognosis.-The prognosis is good. One case has gone into complete remission which has now continued for 3 years, and two have had remissions lasting for from 2 to 3 years. In the remainder there has been considerable relief of symptoms, in spite of evidence in a slightly elevated erythrocyte sedimentation rate of continuing low-grade activity. 
Diagnosis.-The somewhat melodramatic description of their pain by these patients tends to suggest a diagnosis of psychoneurosis until the E.S.R. has been measured. While there may be a functional overlay, the raised E.S.R. points to a systemic disease. The possibility of rheumatoid disease cannot always be excluded despite the absence of overt joint swelling. A period of vague muscle pains may precede the frank signs of this condition and only prolonged observation will establish the diagnosis.

Both polyarteritis nodosa and systemic lupus erythematosus are accompanied by joint and muscle pains. The former commonly includes impairment of renal function, while palpable nodules may be present in the muscles, and the clinical picture is complicated by arterial occlusions in various parts of the body. Despite corticosteroids the prognosis in this condition remains poor. The differential diagnosis of systemic lupus erythematosus may present considerable difficulties; "L.E." cells were not found in the condition now reported and there was no leucopenia. Ankylosing spondylitis in its typical and atypical forms is excluded by the absence of radiological changes in the sacro-iliac joints.

Dermatomyositis is characterized by diffuse muscular weakness and pain, and is accompanied by skin changes resembling scleroderma. The affected muscles have a doughy consistency not found in the condition now reported. Furthermore the E.S.R. is not usually much increased.

Polymyositis resembles the present condition in some respects, but is characterized by increasing muscular weakness which may be accompanied by pain in the affected muscles. It is also often associated with skin changes similar to dermatomyositis, scleroderma, or lupus erythematosus.

Multiple myelomatosis and metastatic carcinomatosis may be excluded by a full radiological examination.

\section{Case Reports}

Case 1, a retired draughtsman aged 65 , first attended the orthopaedic out-patient department on account of back-

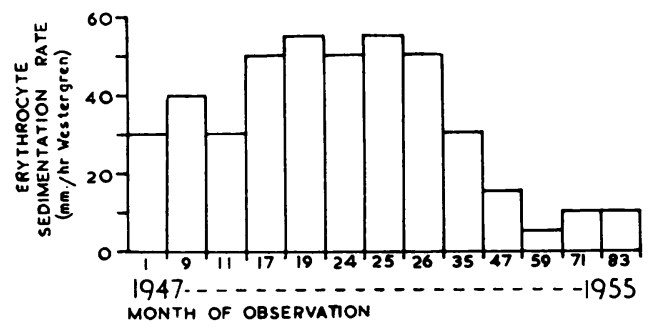

Fig. 1. Case 1. ache of 9 months' duration. Because of a raised E.S.R. without any other objective abnormality, he was admitted to hospital for further investigation in December, 1947. The E.S.R. was $30 \mathrm{~mm}$./hr and the cerebrospinal fluid was normal. He was discharged in January, 1948, without a definite diagnosis, only to be referred to the medical out-patient clinic for the same complaint in the following September. The E.S.R. was then $50 \mathrm{~mm}$. $/ \mathrm{hr}$ and the alkaline phosphatase was 27 units per $100 \mathrm{ml}$. Skiagrams of the spine and sacro-iliac joints showed no abnormality. Physical therapy had afforded no relief and he was referred to the rheumatism clinic in July, 1945.

When seen in this clinic he complained of "pain from the neck to the knees". He was unable to walk more than 50 yds. Since the onset he had lost some $14 \mathrm{lb}$. in weight. He appeared to be in considerable pain but no joint swelling or limitation of movement was found. There was much tenderness in the paravertebral and gluteal muscles. He had some hypertension, with a blood pressure of $200 / 110 \mathrm{~mm}$. Hg, but no other abnormality was found on general physical examination. The laboratory findings are shown in the Table, and the E.S.R. in Fig. 1.

He was given a course of intravenous iron in August, 1949 , and two months later the $\mathrm{Hb}$ had risen to $12 \cdot 85 \mathrm{~g}$. per cent. with a red cell count of $5 \cdot 1$ mill./cu. mm. Some, subjective improvement occurred, but in January, 1950, he reported a recurrence of the pains and the E.S.R. was then found to be $55 \mathrm{~mm}$./hr. Blood investigations included a blood count which again showed some hypochromia with a $\mathrm{Hb}$ of $10.9 \mathrm{~g}$. per cent. and a red cell count of 4.2 mill./cu.mm. The total and differential white cell count were normal. The serum calcium was $10.3 \mathrm{mg}$. and the serum inorganic phosphorus $3.4 \mathrm{mg}$./ $100 \mathrm{ml}$. The urea clearance test gave a standard clearance of 68 per cent. $X$-rays of the cervical and lumbar spines and both hip joints were normal.

As the pains continued and it was felt that he might have an obscure bone condition he was referred to a nearby teaching hospital where bone diseases were receiving special study at the time. The E.S.R. was then $47 \mathrm{~mm}$./hr, serum alkaline phosphatase 15 units $/ 100 \mathrm{ml}$, serum acid phosphatase 3 units/100 ml., and liver function tests normal. He was discharged with the note that no organic disease was considered to be present.

His condition thereafter showed a slow spontaneous improvement, although in November, 1950, the E.S.R. was still $30 \mathrm{~mm} . / \mathrm{hr}$. In October, 1952, he began taking

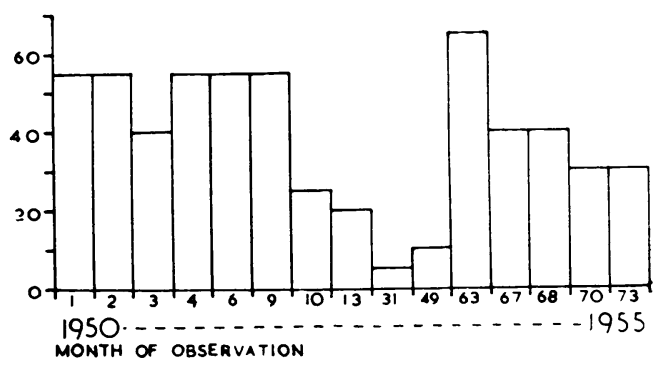

Fig. 2. Case 2. 
Butazolidin and this proved most effective in relieving his symptoms. He was seen again in January, 1953, and the E.S.R. was then normal. He last attended the outpatient clinic in 1955 when he reported himself to be quite fit and had a normal E.S.R.

Case 2, a housewife aged 46, was admitted to the rheumatism unit in January, 1950, with a history of severe pains in the thighs beginning 4 months before and subsequently spreading to the arms, shoulders, and back of the neck. No joint swelling had occurred. Apart from lassitude, there had been no loss of weight or other constitutional symptoms.

On examination she appeared to be somewhat anaemic. No muscular wasting or loss of weight was apparent. The cervical and lumbar spine was much restricted and considerable pain was present in the spinal and shoulder muscles on palpation. No other abnormality was found on general physical examination.

The laboratory findings are given in the Table and the E.S.R. in Fig. 2

Skiagrams of the cervical spine showed some narrowing of the disk space between C6 and C7. No abnormality was seen in the lumbar spine of sacro-iliac joints.

She was discharged in April subjectively improved although the E.S.R. was still elevated at $50 \mathrm{~mm}$./hr. Because of an exacerbation of the pains she was readmitted in July when the E.S.R. was $105 \mathrm{~mm}$./hr and she had hypochromic anaemia with $\mathrm{Hb} 8 \cdot 3 \mathrm{~g}$. per cent. She improved in hospital and was discharged in September, 1950. The E.S.R. was then $25 \mathrm{~mm}$./hr and the $\mathrm{Hb}$ had risen to $11 \cdot 7 \mathrm{~g}$. per cent.

For the next 3 years she was seen in the out-patients clinic at regular intervals. In this time the E.S.R. fell steadily to normal. In July, 1953 , she reported herself to be quite well and the E.S.R. was normal. When seen in December, 1954, she had some recurrence of the pain but the E.S.R. was only $12 \mathrm{~mm}$./hr. By February, 1955, the condition had deteriorated still further, with much pain in the thighs and arms, but no swollen joints or localized pain. Tenderness was again present in the muscles, and she was admitted for further observation.

Laboratory Findings.-E.S.R. $65 \mathrm{~mm} . / \mathrm{hr}$. $\mathrm{Hb} 11 \cdot 7 \mathrm{~g}$. per cent., R.B.C. $3 \cdot 8$ million, W.B.C. 5,600 per cu.mm. Serum albumin $3.9 \mathrm{~g} . / 100 \mathrm{ml}$., serum globulin $2.4 \mathrm{~g}$./ $100 \mathrm{ml}$. Blood urea $20 \mathrm{mg}$. per cent. Urea clearance 67 per cent. of average normal function. Thymol turbidity 1.5 units. No L.E. cells found. Wassermann reaction negative. Differential agglutination test negative.

Further skiagrams of the spine, hands, and feet showed no abnormality.

In hospital she again improved and phenylbutazone afforded much relief of pain. On discharge in July, the E.S.R. was $40 \mathrm{~mm}$./hr and $\mathrm{Hb} 13.2 \mathrm{~g}$. per cent. When last seen in December, 1955, she reported only occasional pain and that she had been able to manage without analgesic drugs. The E.S.R. was $30 \mathrm{~mm}$./hr.

Case $^{\top}$ 3, a housewife aged 48, was transferred to the Devonshire Hospital in May, 1950, from another hospital where she had been admitted with pains in the shoulders, hips, and knees early in November, 1949. At that time she had limitation of the cervical spine, shoulders, and hips, without other abnormality. The investigations at the original hospital, which included a barium meal, blood urea, Widal reaction, Paul Bunnell test, and examination of faeces for occult blood were all negative. The E.S.R. was consistently $40 \mathrm{~mm}$./ $\mathrm{hr}$ (Westergren) and the $\mathrm{Hb} 50$ per cent. Skiagrams of the spine, pelvis, and hips were normal. She had shown no response to a variety of therapies, including anti-histamines, progesterone, penicillin, cincophen, and colchicum.

When she was examined at the Devonshire Hospital the clinical findings were still much the same, namely limitation of the neck and shoulder movements. Her reaction during the examination evoked the comment in the clinical notes that the condition appeared to be largely hysterical. However the finding of a E.S.R. of $100 \mathrm{~mm}$./ $\mathrm{hr}$ (Westergren) made this less likely.

The laboratory findings are given in the Table and the E.S.R. in Fig 3 (overleaf).

Skiagrams of the cervical and lumbar spine and of the pelvis showed no abnormality.

A course of parenteral iron largely corrected the anaemia and the $\mathrm{Hb}$ rose to $12 \cdot 4 \mathrm{~g}$. per cent. Her condition slowly improved and she was discharged in September, 1950, with E.S.R. $30 \mathrm{~mm}$./hr. She continued to attend the out-patient clinic and the variation found in the E.S.R. is recorded in Fig. 3. In February, 1953, she was again admitted to hospital because of recurrence of the pains and extreme depression. Her E.S.R. was only $25 \mathrm{~mm}$./hr (Westergren) and she made a rapid recovery. Since then she has remained free from symptoms, and when seen in May, 1955, the E.S.R. was normal and the sheep cell agglutination test negative.

Case 4, a housewife aged 65, had had a febrile illness in January, 1950, accompanied by pain in the thighs which persisted after the temperature had settled. The pains became generalized, she lost much sleep as a result of the discomfort, and a loss of weight indicated a constitutional effect. No joint swelling had occurred.

She was admitted to hospital in June, 1950, because of persistent pain in the arms and shoulders. Clinically there was some voluntary restriction of movement of the shoulders with no particular tenderness in the muscles and no abnormalities in the joints. General physical examination revealed nothing of note. The laboratory findings are shown in the Table. In hospital the condition showed symptomatic improvement and the E.S.R. settled to normal. She was discharged in August, 1950.

She did not again attend the out-patient clinic, but in October, 1955, when her sister (Case 8) was admitted for an almost identical complaint, she was visited at home. During the 5 years after her discharge from hospital she had continued to have pains in various muscle groups but no joint involvement had occurred. Earlier in the same year she had consulted a cardiologist because of giddiress and tachycardia but no abnormality was found and the electrocardiogram was normal.

Physical examination revealed no evidence of arthritis. 


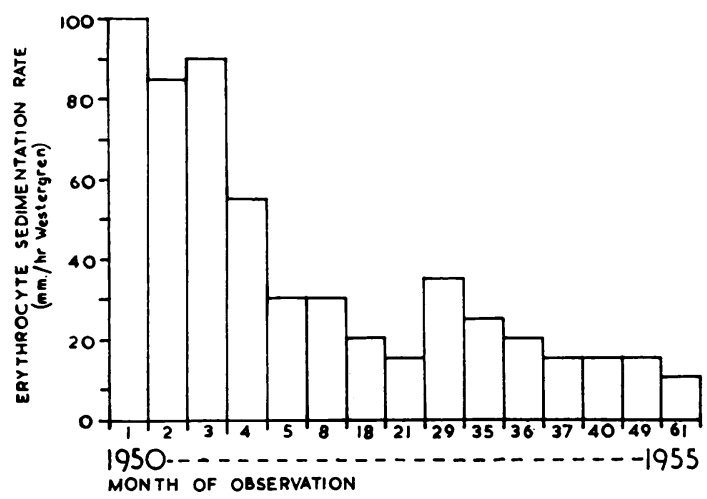

Fig. 3. Case 3.

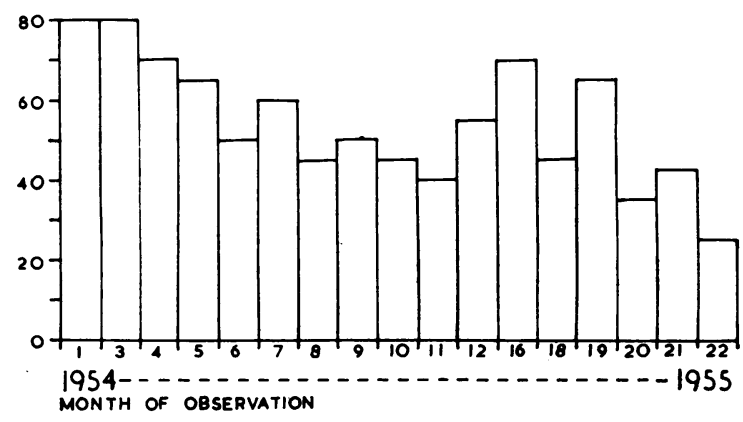

Fig. 4. Case 5 .

comfort in the neck and upper back. Out-patient treatment had afforded no relief and there had been a loss of $18 \mathrm{lb}$. in weight.

On admission she was somewhat anaemic in appearance. A generalized muscular tenderness was present without manifest joint involvement. No abnormality was found on general physical examination. She was apyrexial.

The laboratory findings are shown in the Table.

Skiagrams of the cervical spine, lumbar spine, hands, and feet showed no abnormality.

With rest and a course of parenteral iron, which restored the haemoglobin level to $14.5 \mathrm{~g}$. per cent., her condition improved. The weight increased by $15 \mathrm{lb}$. and the E.S.R. to $40 \mathrm{~mm}$./hr. She was discharged in December, 1954, almost free from symptoms.

A follow-up letter in November, 1955, elicited the report that she was "wonderfully well but still has some discomfort in the shoulders and lower back". physical examination revealed nothing of note. The E.S.R. was $80 \mathrm{~mm}$./hr, and she was admitted to hospital in June, 1954.

The laboratory findings are shown in the Table and the E.S.R. in Fig. 4.

Skiagrams of the hands and feet showed no abnormality, but some degenerative disk changes were present in the cervical and lumbar spines.

She gradually improved in hospital and the pain was largely relieved by calcium aspirin. On discharge in January, 1955, she had gained $14 \mathrm{lb}$. in weight and the E.S.R. was $45 \mathrm{~mm}$./hr. Subsequently, at the out-patient clinic, the E.S.R. remained high and her symptoms persisted. In October, 1955, she began to take prednisone with marked symptomatic improvement. When last seen she still had some shoulder pain and the E.S.R. was $25 \mathrm{~mm}$./hr.

Case 6, a retired schoolmistress aged 68, was transferred from a rheumatic unit to the Devonshire Hospital in July, 1954, with the diagnosis of "fibrositis and osteo-arthritis". In October of the preceding year she had begun to have difficulty in ascending slight inclines because of pain and stiffness in the calf muscles. The pain spread to involve other muscle groups, and by March she had severe dis-

Case 7, a housewife, aged 65, was referred to the rheumatism clinic in January, 1954, because of generalized pain of 3 months' duration. Initially the pains had been confined to both legs extending from the buttocks to the ankles, but in turn the arms, neck, and upper part of the back became affected, so that she had much difficulty in completing her toilet.

She was rather overweight and looked anaemic. The joints were not objectively involved although muscular pain had caused some restriction of shoulder movement. The shoulder muscles were tender on palpation. No significant abnormality was found elsewhere on general physical examination. She was admitted to hospital in February, 1954.

The laboratory findings are given in the Table and the E.S.R. in Fig. 5 (opposite).

Skiagrams of the hands and feet, and cervical and lumbar spine showed only degenerative changes consistent with her age.

After a course of parenteral iron the haemoglobin level rose to $13.4 \mathrm{~g}$. per cent., her general condition improved, and the E.S.R. fell to $50 \mathrm{~mm}$./hr. She was gradually 


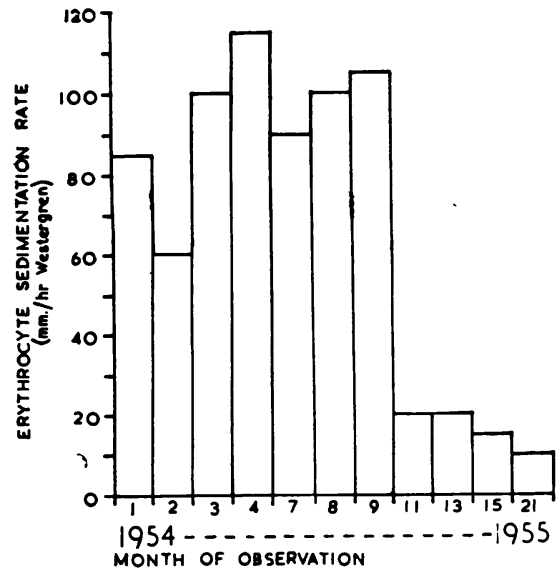

Fig. 5. Case 7.

Case 9, a housewife aged 46, attended the clinic in September, 1953, on account of a stiffness in the upper and lower extremities of 6 months' duration. She had had some difficulty in walking and in negotiating stairs. No loss of weight had occurred but she had apparently had some night sweats. Clinically

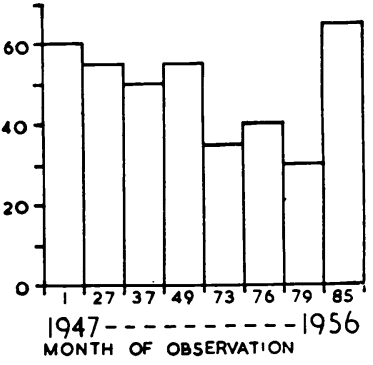

Fig. 6. Case 11. there was no evidence of joint involvement. No abnormality was found on general physical examination. The E.S.R. was 10 $\mathrm{mm} . / \mathrm{hr}$.

In February, 1954, the E.S.R. was $30 \mathrm{~mm} . / \mathrm{hr}$, and by November, 1954 , it had risen to $70 \mathrm{~mm} . / \mathrm{hr}$ and she complained bitterly of pain in the shoulders and legs. She was admitted to hospital in January, 1955.

The laboratory findings are given in the Table.

Skiagrams of the hands, feet,

allowed up, but in April complained of increasing stiffness and the E.S.R. rose to $110 \mathrm{~mm}$. $/ \mathrm{hr}$. In May she began to have a pyrexia accompanied by night sweats and this continued for 6 weeks without ascertainable cause. Blood cultures were sterile, Widal test negative, and urine culture sterile. $X$-rays of the chest showed no abnormality. Nevertheless there was a leucocytosis of 15,800 per cu.mm. with a granulocytosis of 87 per cent. She lost some $28 \mathrm{lb}$. in weight and developed a widespread vitiligo.

The febrile condition gradually cleared up and she was discharged in September, 1954. She continued to improve and was seen regularly as an out-patient. On her last attendance in October, 1955, she still had occasional pains but the E.S.R. was $15 \mathrm{~mm}$./hr and the $\mathrm{Hb} 12 \cdot 6 \mathrm{~g}$. per cent.

Case 8, a widow aged 66, was seen for the first time in February, 1955, when she had had pain in the back of the neck spreading gradually to affect the lower back and legs for the last three months. There had been some morning stiffness but no joint swelling or localization of pain to a joint. The appetite was poor, she had lost weight. Salicylates afforded some relief. Her sister (Case 4) had been an in-patient for a similar complaint some years before.

She had Heberden's nodes, and the back and gluteal muscles were markedly tender on palpation. She had some hypertension (blood pressure $230 / 110 \mathrm{~mm}$. $\mathrm{Hg}$ ). No other significant abnormality was found on general physical examination.

The laboratory findings are shown in the Table.

Skiagrams of the hands, feet, and spine showed only minor degenerative changes.

In hospital there was a gradual improvement with rest, and her pains were much relieved by phenylbutazone. She was discharged in June, 1955, but continued to attend the clinic. When last seen in October she was practically free from symptoms and the E.S.R. was $25 \mathrm{~mm}$. (Westergren). spine, and chest showed no abnormality.

In hospital her condition gradually improved and calcium aspirin afforded adequate relief of symptoms. On discharge in March, 1955, the E.S.R. was still $60 \mathrm{~mm}$./hr but she was free from pain. She attended the clinic regularly and the improvement was maintained. In November, 1955, the E.S.R. was $10 \mathrm{~mm}$./hr.

Case 10, a housewife aged 62, had suffered a sudden attack of generalized pain in May, 1955, which improved after a period of rest in bed. Intermittent attacks of pain continued until September when she found that she could no longer climb stairs. She was not able to complete her toilet, became very depressed, and lost her appetite and some weight. Her sleep was much disturbed by pain.

She was referred to the clinic in November, 1955. She then had severe pains across the shoulders, down the arms and in the back. Some discomfort was present in the legs at night. She appeared to be rather anaemic but no considerable loss of weight appeared to have occurred. No objective joint changes were found, but the cervical spine was limited in range and full shoulder abduction was not possible because of the painful shoulder muscles. Nothing of note was detected in the lungs, cardiovascular system, abdomen, or central nervous system. She was admitted to hospital shortly afterwards.

The laboratory findings are given in the Table.

Skiagrams of the spine, pelvis, hands, and feet showed no abnormality.

With rest in bed she gradually improved and her recovery was hastened after she began taking prednisone. When she was discharged towards the end of January, 1956, she was free from symptoms and the E.S.R. was normal. She continued taking prednisone in a dosage of $5 \mathrm{mg}$. daily and remained largely symptom-free, but on the last occasion that she attended the clinic the E.S.R. had again risen to $40 \mathrm{~mm}$. $/ \mathrm{hr}$.

Case 11, a retired engineer aged 59, first attended the out-patient clinic in 1947, having begun to have pains 
"all over" 3 years before. This was accompanied by stiffness on rising in the morning and after remaining in one position for any length of time. The shoulder girdle was mainly involved but no joint limitation was present. General physical examination disclosed no abnormality other than a nodular lipomatosis affecting the upper limbs. The E.S.R. was $58 \mathrm{~mm} . / \mathrm{hr}$ and the blood uric acid $2.65 \mathrm{mg}$. per cent.

In July, 1950, he again attended the out-patient clinic because of pain in the shoulders, neck, and lower back. He also described a burning, searing pain in the left shin, knee, and hip. No objective abnormality was present, but the E.S.R. was $50 \mathrm{~mm}$. $/ \mathrm{hr}$. He was treated as an out-patient, but showed no symptomatic improvement.

He was referred to the clinic in 1953, still with pain in the shoulders radiating into the neck. As before no clinical abnormality was found, the E.S.R. was $55 \mathrm{~mm}$. $/ \mathrm{hr}$.

In July, 1955, he again attended the out-patient clinic with a complaint of pain all over-sometimes in the shoulders, at other times in the fingers or both knee joints. No swelling of the joints had occurred and no abnormality was found on examination other than the lipomatosis which had now spread to the trunk and lower limbs.

The laboratory findings are shown in the Table and the E.S.R. in Fig. 6.

When last seen in July, 1956, he reported himself to be free from symptoms, but the E.S.R. was still raised at $65 \mathrm{~mm} . / \mathrm{hr}$.

Case 12, a schoolmistress aged 61, consulted me on account of pain in both shoulders and groins in July, 1954. The onset had occurred in April with a stiff neck accompanied by pain radiating into the shoulders. She had been admitted to her local hospital in May, but had been discharged 3 weeks later without a definite diagnosis being reached.

In September, 1954, when she was admitted to the Devonshire Hospital, she had pain on movement of the shoulders, cervical spine, and hips. No abnormality was found on general physical examination.

The laboratory findings are shown in the Table.

$X$-rays showed no abnormality other than the degenerative changes to be anticipated at her age in the cervical spine, lumbar spine, and pelvis.

The condition gradually improved with rest in bed and daily active non-weight-bearing exercises. Calcium aspirin proved an adequate analgesic. The E.S.R. remained at levels of over $100 \mathrm{~mm}$./hr. She was discharged in December, 1954, much improved subjectively.

It was not possible to see her again after she left hospital but a follow-up letter in April, 1956, was answered by her private doctor who wrote: "She feels and is very well and walks quite a lot about the town without any discomfort."

\section{Discussion}

The question posed by this condition is one of identity-is it but the precursor of rheumatoid disease, or does it form a clinical entity within the group of the rheumatic diseases? Kersley (1951) drew attention to a similar condition when he reported a series of thirteen patients who had had an acute onset of severe muscular pain and tenderness accompanied by a raised sedimentation rate without signs of arthritis. Apart from some degenerative changes, the $x$-ray appearances were normal, and muscle biopsy in four cases showed no pathological changes. Loss of weight and anaemia had occurred in some patients and a few were pyrexial. The pain was widespread and affected in particular the shoulders and thigh muscles. The cases were kept under observation for 6 months or more after the onset, but none developed typical polyarticular changes.

No further records of a comparable syndrome appeared until Bagratuni (1953) published the description of a febrile illness in seven patients characterized by a oneralized aching confined most often to the shoulcisrs ind cervical region without swelling or redness of the joints. The constitutional effects were manifested by a persistent fever, anaemia, and loss of weight. In all cases the sedimentation rate was extremely high, leucocytosis was present in three, and one showed an inversion of the albumin/globulin ratio. Radiologically only degenerative changes were found, principally in the cervical spine.

Kersley considered that his cases were probably atypical manifestations of a rheumatoid syndrome, although no signs of joint involvement had appeared, and Bagratuni also concluded that the condition described was a syndrome more closely related to rheumatoid arthritis than to the other collagen diseases. Some of his cases were followed for 12 months without developing clinical arthritis.

In some respects the condition resembles one reported by Shy and McEachern (1951), as a form of myopathy occurring predominantly in women during and after the climacteric. It was characterized by a painless progressive weakness of the hip and shoulder muscles. The erythrocyte sedimentation rate in these cases is not recorded, but some abnormality of creatine and creatinine metabolism was found and muscle biopsy was consistent with the findings in a myopathy. A good response to steroid therapy was obtained in some of these cases. It is noteworthy that pain was absent in this condition.

The report of a discussion on the clinical aspects of polymyositis (Nattrass, 1956; Walton, 1956) suggests that this disease may be closely allied. Nevertheless, from the description, differences are apparent. Four clinical groups are identified, in all of which muscular weakness, wasting, and sometimes pain are so obtrusive that many cases are initially diagnosed as suffering from muscular dystrophy. 
One group contains cases of severe rheumatoid arthritis with secondary polymyositis and skin changes resembling exfoliative dermatitis:

"seborrhoeic dermatitis, lupus erythematosus, or scleroderma. Similarly to the condition now described, polymyositis, when not associated with malignant disease, either improved spontaneously, becomes arrested or responds to steroid therapy. In none of the present series was there found a muscular weakness or atrophy suggestive of a muscular dystrophy nor did this develop during the course of the disease."

The cases described by Kersley (1951) and by Bagratuni (1953) closely resemble the condition reported in the present paper, and it seems very probable that it is the same syndrome. Much in the symptomatology is suggestive of the prodromata of rheumatoid disease, and two of the patients described above (Cases 2 and $3^{\prime}$ were thought for some time to be suffering from rheumatoid arthritis. The absence of the characteristic joint involvement led to a review of the diagnosis. It has now been possible to observe a number of the patients over a period of years, during which time some have apparently gone into a complete remission and none has developed a frank arthritis. The differential sheep cell agglutination test proved to be negative in all cases in which it was carried out.

It must be emphasized that the diagnosis, based so largely on negative findings (the absence of joint involvement, and muscle weakness, or atrophy) can only be made after a lengthy period of observation. In rheumatoid disease particularly, the onset of overt joint involvement may be preceded by many months of vague muscular pains.

There must be substantial agreement with Kellgren (1952) that it would be more profitable to abandon the unitarian concept of the rheumatic diseases. It seems of little service to regard this syndrome as a variation of a disease generally recognized by the presence of joint swelling or deformity. Nevertheless, the response of the syndrome to steroid therapy and to phenylbutazone indicates a relationship to the so-called collagen diseases. It may be premature to suggest that the condition is a clinical entity, but there appear to be sound reasons for regarding it as such. The two earlier reports both referred to the syndrome as occurring in the "aged" or "elderly", the lowest ages being respectively 64 and 57 years. In the present series the age at onset varied from 46 to 68 years, hardly to be regarded as "aged". If a descriptive label is to be used for the condition it would be unrealistic to include a reference to age, and until more is known about it I suggest the term "polymyalgia rheumatica".

\section{Summary}

(1) A condition characterized by widespread muscular pains without arthritis but accompanied by a high erythrocyte sedimentation rate and occasional pyrexia is described.

(2) The relationship to rheumatoid disease is discussed and it is concluded that this is probably a clinical entity within the rheumatic group of diseases.

(3) It is proposed to term the syndrome "polymyalgia rheumatica".

I am grateful to Professor J. H. Kellgren who kindly undertook to examine all the $X$-ray films of the cases and confirmed that there was no evidence of arthritis, and Dr. J. Ball for the many sheep cell agglutination tests he has carried out on these cases.

\section{REFERENCES}

Ball, J. (1956). Personal communication.

Bagratuni, L. (1953). Annals of the Rheumatic Diseases, 12, 98.

Kellgren, J. H. (1952). Brit. med. J., 1, 1093.

Kersley, G. D. (1951). "II Congreso Europeo de Reumatologia-

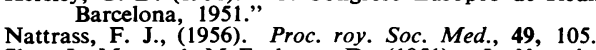

Shy, J. M., and McEachern, D. (1951). J. Neurol. Neurosurg. Psychiat., 14, 101.

Walton, J. N. (1956). Proc. roy. Soc. Med., 49, 107.

\section{Syndrome myalgique avec effets diathésiques Polymyalgia rheumatica \\ RÉSUMÉ}

(1) On décrit un état caractérisé par des douleurs musculaires très étendues, sans arthrite, mais accompagné d'une vitesse de sédimentation érythrocytaire élevée et de pyrexie occasionnelle.

(2) On discute ses ressemblances avec la maladie rhumatismale et on conclue que l'on a probablement à faire à une entité clinique appartenant au groupe des maladies rhumatismales.

(3) On propose d'appeller ce syndrome "polymyalgia rheumatica".

\section{Síndrome miálgico con efectos diatésicos Polymyalgia rheumatica}

(1) Se describe una afección caracterizada por dolores musculares muy extensos, sin artritis, pero con una velocidad de sedimentación eritrocitaria alta $y$ con pirexia de vez en cuando.

(2) Se discute su relación con la enfermedad reumática y se concluye que se trata aquí probablemente de una entidad clínica perteneciendo al grupo de las enfermedades reumáticas.

(3) Se propone llamar este síndrome "polymyalgia rheumatica". 


\title{
CORRIGENDA
}

Volume 16, pp. 230-237

\section{MYALGIC SYNDROME WITH CONSTITUTIONAL EFFECTS POLYMYALGIA RHEUMATICA}

\author{
BY \\ H. STUART BARBER \\ From the Rheumatism Unit, Withington Hospital, Manchester, and the Devonshire Royal Hospital, Buxton
}

Page 234, Column 2, Line 14, to read:

... The weight increased by $15 \mathrm{lb}$. and the E.S.R. fell to $40 \mathrm{~mm}$. $/ \mathrm{hr}$.

Page 236, Column 2, Last paragraph, to read:

The report of a discussion on the clinical aspects of polymyositis (Nattrass, 1956; Walton, 1956) suggests that this disease may be closely allied. Nevertheless, from the description, differences are apparent. Four clinical groups are identified, in all of which muscular weakness, wasting, and sometimes pain are so obtrusive that many cases are initially diagnosed as suffering from muscular dystrophy. One group contains cases of severe rheumatoid arthritis with secondary polymyositis and skin changes resembling exfoliative dermatitis, seborrhoeic dermatitis, lupus erythe- matosus, or scleroderma. Similarly to the condition now described, polymyositis, when not associated with malignant disease, either improves spontaneously, becomes arrested, or responds to steroid therapy. In none of the present series was there found a muscular weakness or atrophy suggestive of a muscular dystrophy nor did this develop during the course of the disease.

Page 237, Column 2, Paragraph 4, to read:

I am grateful to Professor J. H. Kellgren who kindly undertook to examine all the $X$-ray films of the cases and confirmed that there was no evidence of rheumatoid arthritis, and to Dr. J. Ball for the many sheep cell agglutination tests he has carried out on these cases. 